Education Act, 194 48 (195I), Summary of legislation and directory of oiganis ions for the care of the physically handicapped, p. 42, Central Council for Care of Cripples. Hernemann,
London.

GUTTMANN, L 1946), Brit. f. Phys. Med., 9, 6.

HILL, A. (1046), 'گirt versus Illness,' Williams \& Norgate, London. JONES, M. S. (1944), Brit. F. Phys. Med., 7, I.

JONES, M. S. (1950), Ibid., 13, I I.

JONES, M. S. (1951), Lancet, ii, 7.

Ministry of Education Circular I5 (1945), Educational provision

for civilian patients in hospitals and sanatoria.

Ministry of Health Circular EMS 34/344 (1943), Hospital patien engaged in productive work. Ministry of Health Circular $5 / 45$ (1945), Educational provision fer
civilian patients in hospitals and sanatoria.

Ministry of Labour (1 949), Second report of the Standing Committere on the rehabilitation and resettlement of disabled persories p. Io, D.37. H.M. Stationery Office. 36/176.

Preparatory Training Bureau, British Council for Rehabilitation Tavistock House, Tavistock Square, London, W.C.I.

WARREN, M. W. (1950), 'Geriatrics. Recent Advances Physical Medicine,'p. 321. Churchill London.

\title{
'GOITRE PLONGEANT
}

By J. N. HaRris-Jones, M.D., M.R.C.P.

Senior Medical Registrar, Royal Hospital, Sheffeld

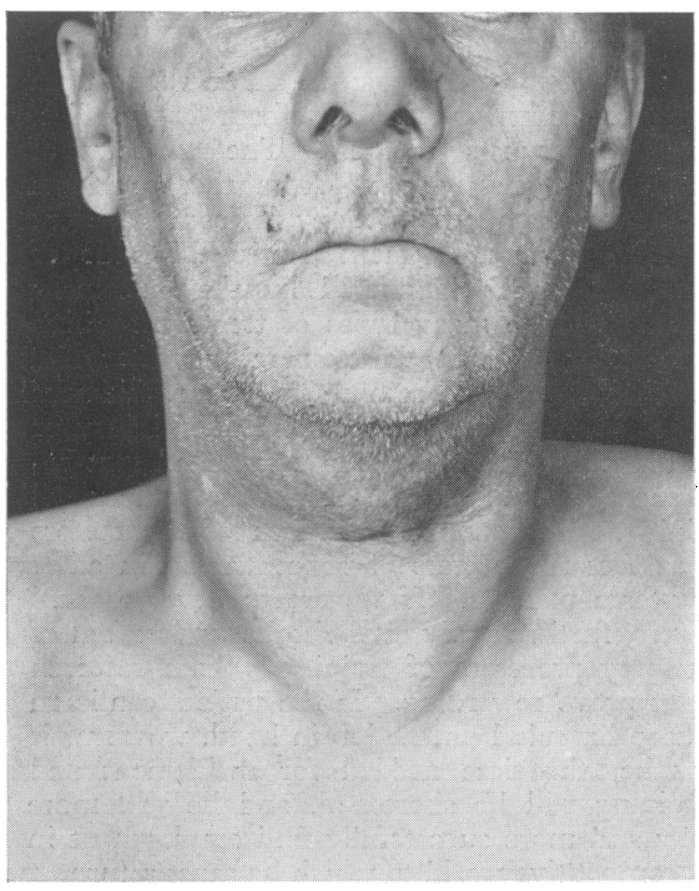

Fig. ra.-Patient at rest.

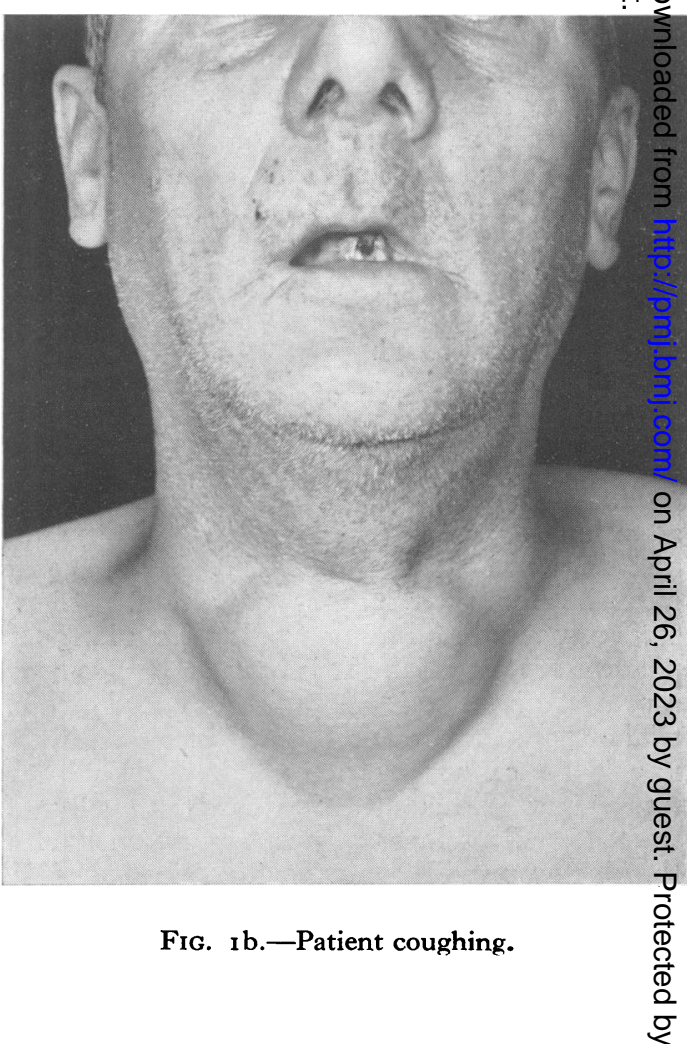


It appears that thyroid tumours described under the title of 'goitre plongeant' may be of two types. The majority of writers have described cases in which there has been a relatively fixed thyroid tumour with an extensive retrosternal prolongation. The French literature contains many references to this type, the papers by Brull (1929) and Van den Wildenburg (1947) being particularly instructive. Less common are the reports of the more mobile type of goiterous enlargement which plunges freely from neck to thorax. Wakeley (I939), who until recently had published the only English contribution on this topic, reported two cases belonging to this second group.

The present case is reported because the diffuse calcification of the thyroid tumour permitted unusually clear radiological demonstration of its mobility.

\section{Case Report}

A miner, aged 56 years, sought medical advice for progressive dyspnoea of effort. $\mathrm{He}$ had suffered from winter bronchitis for some thirty years and had a moderately productive cough. There was recently slight dysphagia. Over the last six years he and others had noticed the occasional appearance of a mass in his neck, but this

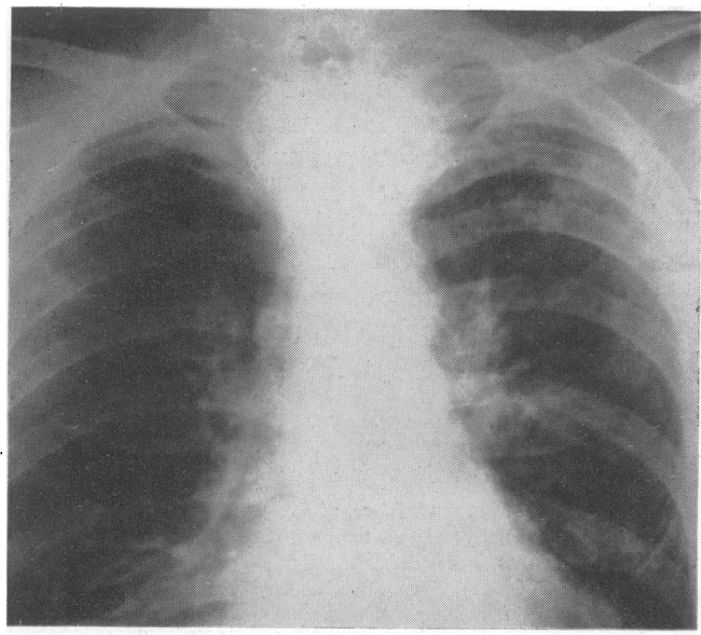

Fig. 2a.-Anteroposterior X-ray. Patient at rest.

Fig. 2b.-Anteroposterior X-ray. Patient having swallowed. had caused him no concern as he had attributed his symptoms to his chest complaint.

Examination showed him to be well developed, but in slight respiratory distress with a faint inspiratory stridor. He had a 'brassy' cough, slight ptosis of the right upper lid, but there was no evidence of superior vena caval block.

At rest the neck was of almost normal contour, but on coughing or swallowing it ballooned out in a most alarming manner, returning to normal at the end of the act of swallowing or paroxysm of coughing (Fig. I, a and b). The patient could produce this tumour at will, and retain it in its cervical position by extending the neck, or by placing a finger below its inferior border. So mobile was it in fact, that it would slip from between the examining fingers and plunge back into its retrosternal bed where only its superior surface was palpable at the level of the suprasternal notch. Absence of thrills or bruit suggested poor vascularization. The trachea was in the midline but displaced backwards. Physical examination revealed marked bronchospasm and emphysema; there was no evidence of disordered thyroid function.

The patient was admitted for investigation and found to be euthyroid. Radiographs supplied striking confirmation of the clinical diagnosis of

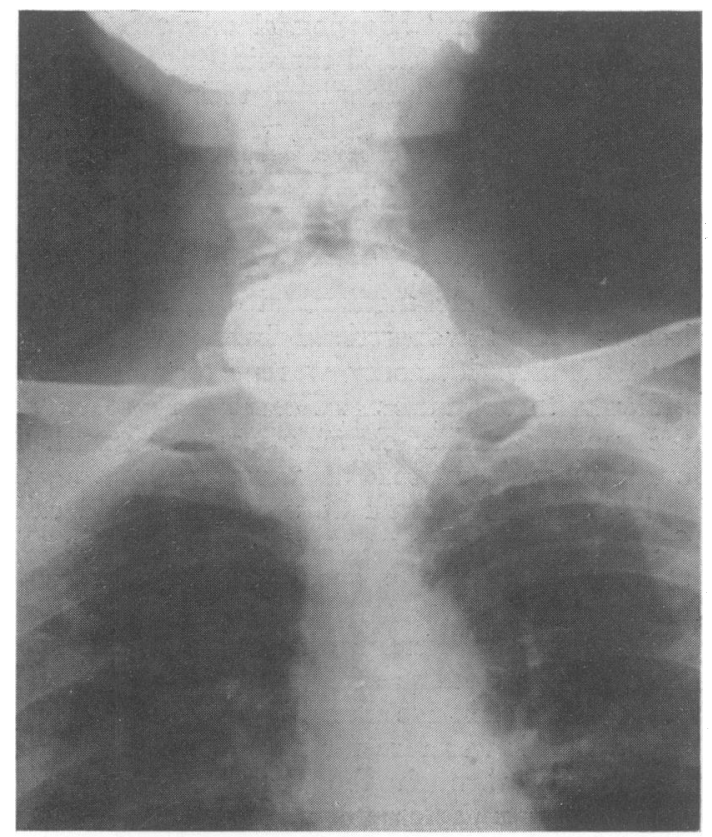




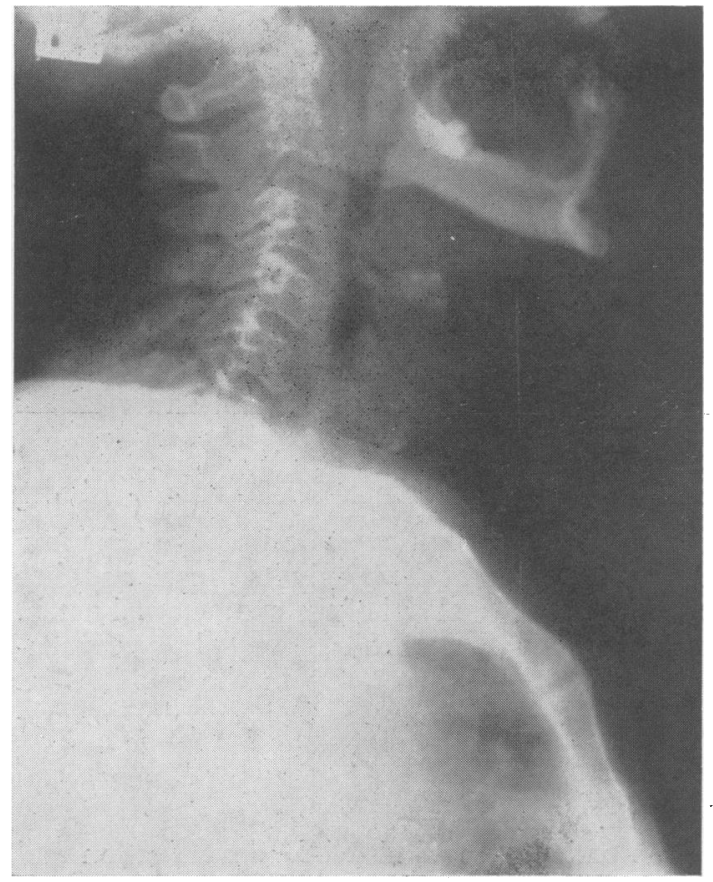

FIg. 3a.-Lateral X-ray. Patient at rest.

' goitre plongeant,' showing clearly the mobility of this diffusely calcified thyroid (Figs. 2 and 3 ). Although it was recognized that most of his symptoms were caused by the chest condition, thyroidectomy was advised because such tumours may become impacted in the thorax if their volume is suddenly increased due to cystic degeneration or to haemorrhage. This complication may be followed by acute mediastinal obstruction, or at least increase the operative hazard.

Partial thyroidectomy was performed without difficulty through the usual cervical approach, and the post-operative course was uneventful. A cystic mass $6 \mathrm{~cm}$. in diameter was removed, the walls of which showed diffuse fibrosis and calcification, but there was thyroid tissue to be seen at the edges of the specimen on microscopic examination.

Much of the literature on this subject is confined to descriptions of fixed retrosternal goitres and their obstructive phenomena. Berard (1923) stated that it was rare for an enlarged thyroid to pass freely through the thoracic inlet. Iselin (1913) reports the case of a lady singer, who was obliged to retain her goitre in its thoracic position by digital pressure, because when in full voice it

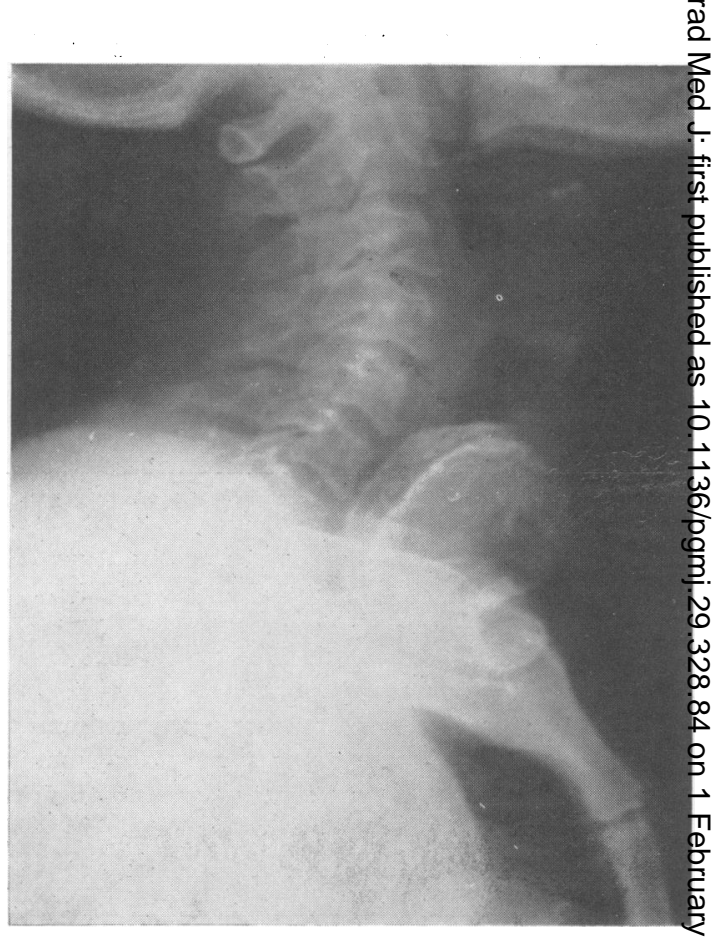

FIG. 3b.-Lateral X-ray. Patient having swallow高

would ascend to the neck and cause considerab vocal and cosmetic embarrassment.

It is suggested that the term ' goitre plongeant $\frac{2}{3}$ should be reserved for cases such as that reporteg here, in which the tumour moves freely throug $b$ the thoracic inlet. Because impaction at the narrow thoracic inlet or in the thorax is likely these cases, operative removal is advisable.

I should like to record my gratitude to $\mathrm{D}$ C. G. Imrie for his help and advice.

\section{BIBLIOGRAPHY} BERARD, HENRY and MOREL (1936), Lyon Chir., 33, 635

BERARD, L., and PONTHUS, P. (1937), Bull. Soc. radiol. me France, 25, $100-102$.

BRULL, L. (1947), Rev. med. Liege, 2, 629-631.

CHALIER, A (1906), Lyon med., 106, 625-628.

DARTIGUES (1912), Paris chirurg., 4, 969-97 I.

GUILLEMINET (1920), Lyon med., 129, 480.

ISELIN (1913), Paris chirurg., 5, 25 I.

JEANENNEY, G., and ROUSSEAU, M. (1936), F. med. Bordeau II3, 759.

KRECKE, A. (1920), Munchen. med. Wchnschr., 67, $37 \mathrm{I}$. LUQUET, M. G. (1936), Technigue Chirurgicale, 28, 143-166. PERRIN (1924), Lyon chirurg., 21, 215-219.

PORTMANN, G. (1920), $\mathcal{F}$. de med. de bordeaux, 50, ror. THIRIAR, R. (1937), Bull. Acad. med. Roumanie, 3, 376-384. VELLACOTT (1952), Medicine Illustrated, 6, I I I-I I4.

WAKELEY, C. P. G. (1939), Clin. $\mathcal{F} ., 68,349-351$.

WILDENBURG, L. VAN DEN (1929-30), Arch. fr. belg. chir 32, 23-29. 